\title{
Is There a Yet Unreported Unbalanced Chromosomal Abnormality without Phenotypic Consequences in Proximal 4p?
}

\author{
T. Liehr $^{a} \quad$ I. Bartels ${ }^{b} \quad$ B. Zoll ${ }^{b} \quad$ E. Ewers $^{a} \quad$ K. Mrasek $^{a} \quad$ N. Kosyakova ${ }^{a}$ \\ M. Merkas ${ }^{a, c}$ A.B. Hamid ${ }^{a}$ F. von Eggeling ${ }^{a} \quad$ N. Posorski ${ }^{a} \quad$ A. Weise ${ }^{a}$ \\ a Jena University Hospital, Institute of Human Genetics, Jena, and ${ }^{b}$ Institute of Human Genetics, Göttingen, \\ Germany; ' School of Medicine Zagreb University, Croatian Institute for Brain Research, Zagreb, Croatia
}

\section{Key Words}

4p14 · Duplication · Small supernumerary marker

chromosome $\cdot$ Unbalanced chromosomal abnormalities

\begin{abstract}
Unbalanced chromosomal abnormalities (UBCA) are reported for $>50$ euchromatic regions of almost all human autosomes. UBCA are comprised of a few megabases of DNA, and carriers are in many cases clinically healthy. Here we report on a partial trisomy of chromosome 4 of the centromerenear region of the short arm of chromosome 4 present as a small supernumerary marker chromosome (sSMC). The sSMC was present in $>70 \%$ of amnion cells and in $60 \%$ of placenta. Further delineation of the size of the duplicated region was done by molecular cytogenetics and array comparative genomic hybridization. Even though the sSMC lead to a partial trisomy of $\sim 9$ megabase pairs, a healthy child was born, developing normally at 1 year of age. No comparable cases are available in the literature. Thus, we discuss here the possibility of having found a yet unrecognized chromosomal region subject to UBCA.

Copyright $\odot 2010$ S. Karger AG, Basel
\end{abstract}

The finding of unbalanced chromosomal abnormalities (UBCA) was recently reviewed and summarized from a total of 200 families [Barber, 2005; http://www. ngrl.org.uk/Wessex/collection/ubca_chart.htm]. UBCA usually involve several megabases of DNA, and carriers of such UBCA are ascertained either through an abnormal phenotype, adverse reproductive effects or by chance [Liehr et al., 2009].

Here, we report a possibly new chromosomal region involved in cytogenetic UBCA in a case detected through prenatal diagnosis. The indication for amniocentesis was nuchal translucency of $3.9 \mathrm{~mm}$ in week $14+3$, with a nasal bone of $1.5 \mathrm{~mm}$ in week 13 . Cytogenetic analysis revealed a karyotype mos $47, \mathrm{XX},+\operatorname{mar}[29] / 46, \mathrm{XX}[12]$ in 3 independent amniotic fluid cell cultures. The origin of the small supernumerary marker chromosome (sSMC; for sSMC see also http://www.med.uni-jena.de/fish/ sSMC/00START.htm) was determined to be from chromosome 4 by multiplex fluorescence in situ hybridization (M-FISH) [Speicher et al., 1996; see fig. 1A]. By subcentromere-specific M-FISH (subcenM-FISH) [Starke et al., 2003], it was shown that only centromere-near short-arm material was present on the sSMC (fig. 1B), and arrayproven multicolor banding (aMCB) [Weise et al., 2008] suggested that the sSMC was derived from $4 \mathrm{p} 14 \sim \mathrm{p} 13$ to 4q11.1 (fig. 1C). Array comparative genomic hybridiza-

Dr. Thomas Liehr

Institut für Humangenetik

Kollegiengasse 10

DE-07740 Jena (Germany)

Tel. +493641935 533, Fax +493641935 582, E-Mail i8lith@mti.uni-jena.de 

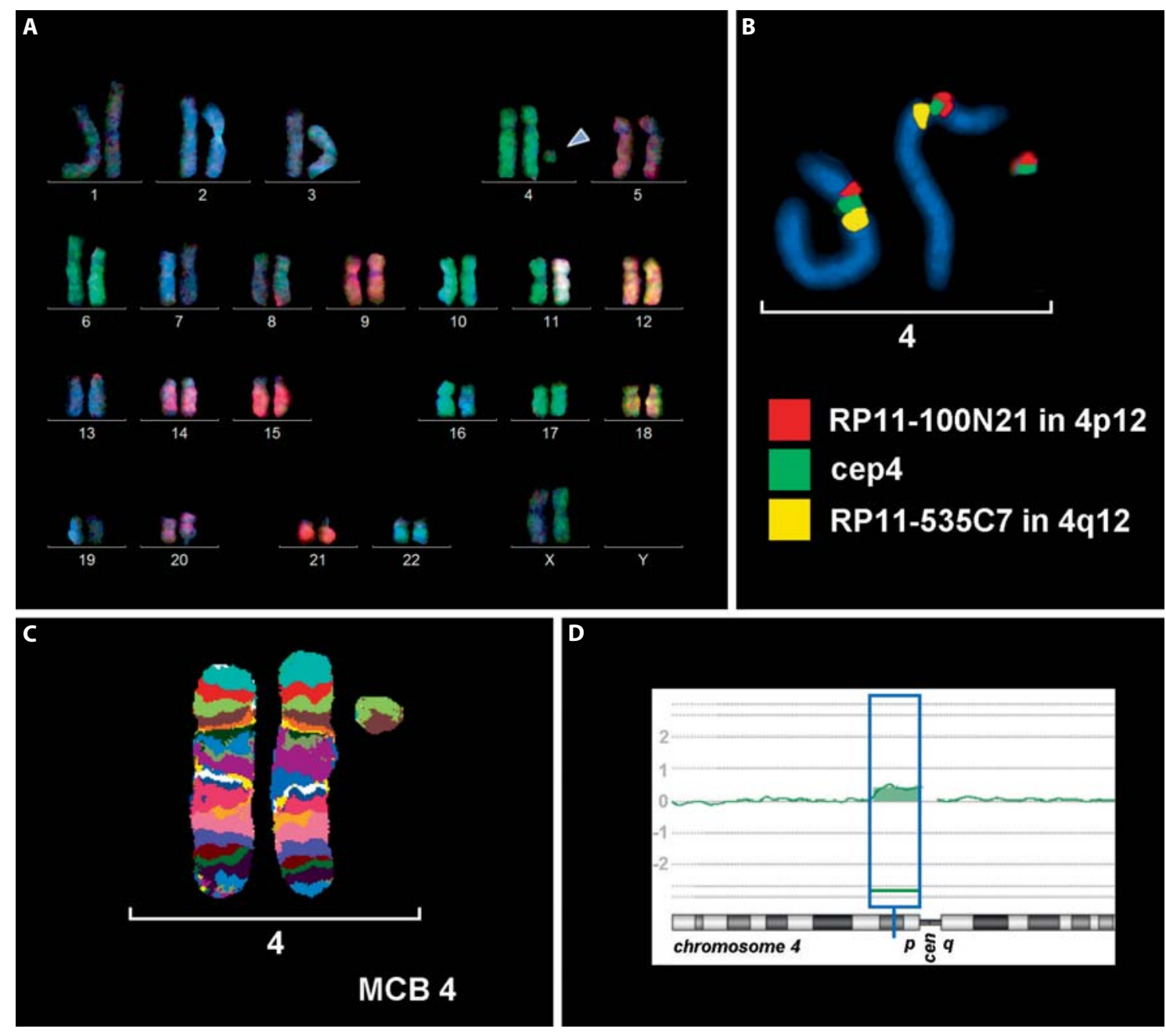

Fig. 1. A M-FISH result showing an sSMC derived from chromosome 4 (arrowhead). B The breakpoint in the long arm of the sSMC could be characterized by subcenM-FISH as $4 \mathrm{q} 11.1$, as no signal was available using the BAC in $4 \mathrm{q} 12$ (yellow). cep = Centromeric probe. C Array-proven multicolor banding (aMCB) characterized the sSMC breakpoint in the short arm as $4 \mathrm{p} 14 \sim \mathrm{p} 13$. D Array-CGH showed a gain of copy number between 39.8 to 48.9 $\mathrm{Mb}$ of chromosome 4 and narrowed down the short arm breakpoint to $4 \mathrm{p} 14$. cen $=$ Centromere; $\mathrm{p}=$ short $\operatorname{arm}, \mathrm{q}=$ long arm. tion (array-CGH) done according to the manufacturer's instructions using whole genomic DNA confirmed and refined these results (fig. 1D). The sSMC lead according to Agilent platform using a $44 \mathrm{~K}$ chip to gain of copy number of $39,799,760$ to $48,924,359 \mathrm{bp}$. Thus, the final karyotype was mos 47,XX,+min(4)(:p14->q11.1:)[29]/46,XX[12]; the karyotype is given according to Liehr [2009], describing a centric minute shaped sSMC. Marker analysis ruled out uniparental disomy 4 . After genetic counseling, the parents opted for the pregnancy.

At birth, placental cells and fibroblast cultures from the umbilical cord were analyzed. Interphase FISH using a centromere-specific probe for chromosome 4 revealed 3 specific signals in $60 \%$ of the placental nuclei and chromosome analysis confirmed mosaicism in fibroblasts as well. Parents refused cytogenetic analysis of peripheral blood. The parental chromosomes were normal.

A healthy girl was born at week 39 with a weight of $3,740 \mathrm{~g}$. The baby was phenotypically normal and developed normally during the time of monitoring, i.e. until the age of 1 year.

Here we report the first case with an sSMC derived from 4 p14 to $4 \mathrm{q} 11.1$ present in the mosaic of $60-72 \%$ of the studied cells, leading to only minor clinical symp- 
toms with respect to the size of the observed imbalance. At the age of 3 years 6 months, the patient has no external malformations and size, weight and head circumference are all at the 50th percentile. She showed slight psychomotor retardation, i.e. sitting at 8 months, walking at 1 year of age, delayed language development, and now speaking 4-5-word sentences. The size of the duplicated region is $8.9 \mathrm{Mb}$, which is a common size for UBCA (http://www.med.uni-jena.de/fish/sSMC/00START. $\mathrm{htm})$. The region is known to be comprised of many copy number variations and other repetitive elements [Jackson et al., 1999; Iafrate et al., 2004], but also contains more than 40 genes of which 22 have 'OMIM numbers' and at least 2 of which are associated with late-onset neurological conditions. Maybe it has also to be considered that the mosaicism present in the reported case could also be responsible for the lack of symptoms, as it has recently been shown that different body tissues can vary significantly in mosaic-expression of sSMC carriers [Fickelscher et al., 2007].

Overall, apart from the case reported here, there is no comparable case in the literature with such a small imbalance in $4 \mathrm{p}$; there is only a larger one which includes $4 \mathrm{p} 16$ to 4 p12 reported by Kakinuma et al. [2008]. Thus, we have to wait for further reports on duplications to clarify the question if proximal $4 \mathrm{q}$ may harbor a UBCA.

\section{Acknowledgments}

This work was supported in parts by DAAD (D07/00070), BMBF/DLR (BLR 08/004 and ARM 08/001), Prochance 2008 and 2009, and DFG (LI 820/22-1).

\section{References}

Barber JC: Directly transmitted unbalanced chromosome abnormalities and euchromatic variants. J Med Genet 42:609-629 (2005).

- Fickelscher I, Starke H, Schulze E, Ernst G, Kosyakova N, et al: A further case with a small supernumerary marker chromosome (sSMC) derived from chromosome 1 evidence for high variability in mosaicism in different tissues of sSMC carriers. Prenat Diagn 27:783-785 (2007)

Iafrate AJ, Feuk L, Rivera MN, Listewnik ML, Donahoe PK, et al: Detection of large-scale variation in the human genome. Nat Genet 36:949-951 (2004).

Jackson MS, Rocchi M, Thompson G, Hearn T, Crosier M, et al: Sequences flanking the centromere of human chromosome 10 are a complex patchwork of arm-specific sequences, stable duplications and unstable sequences with homologies to telomeric and other centromeric locations. Hum Mol Genet 8: 205-215 (1999).
Kakinuma H, Ozaki M, Sato H, Takahashi H: Variation in GABA-A subunit gene copy number in an autistic patient with mosaic 4 $\mathrm{p}$ duplication (p12p16). Am J Med Genet B 147:973-975 (2008).

Liehr T: Small supernumerary marker chromosomes (sSMCs): a spotlight on some nomenclature problems. J Histochem Cytochem 57: 991-993 (2009).

Liehr T, Stumm M, Wegner RD, Bhatt S, Hickmann P, et al: 10 p11.2 to $10 \mathrm{q} 11.2$ is a yet unreported region leading to unbalanced chromosomal abnormalities without phenotypic consequences. Cytogenet Genome Res 124: 102-105 (2009).
Speicher MR, Gwyn Ballard S, Ward DC: Karyotyping human chromosomes by combinatorial multi-fluor FISH. Nat Genet 12:368-375 (1996).

-Starke H, Nietzel A, Weise A, Heller A, Mrasek $\mathrm{K}$, et al: Small supernumerary marker chromosomes (SMCs): genotype-phenotype correlation and classification. Hum Genet 114 51-67 (2003).

Weise A, Mrasek K, Fickelscher I, Claussen U, Cheung SW, et al: Molecular definition of high resolution multicolor banding (MCB) probes - first within the human DNA-sequence anchored FISH-banding probe set. J Histochem Cytochem 56:487-493 (2008). 